\title{
Determinan Faktor Perputaran Karyawan Menggunakan Structural Equation Modeling (SEM)
}

\author{
Yustinus Yuniarto $^{1) *}$ dan Titin Fani Fadilah ${ }^{2)}$ \\ ${ }^{1)}$ Manajemen/Fakultas Ilmu Sosial dan Humaniora, Universitas Bunda Mulia \\ 2) Manajemen/Fakultas Ilmu Sosial dan Humaniora, Universitas Bunda Mulia
}

Diterima 15 Agustus 2019 / Disetujui 16 September 2019

\begin{abstract}
Business competition in this case shows the public demand and supply in this case applies. The development of the business world is able to provide offers that tend to be more attractive to both experienced and non-experienced Human Resource. This makes employees in a company in a certain period tend to have consideration to move and choose more attractive offers from other companies. This study generally aims to analyze the determinants of employee turnover factors. This research is a quantitative study using Structural Equation Modeling (SEM) with a total sample of 50 people with analysis tools, namely SMART PLS 3.0. The results of this study explain in a direct effect that employee motivation is not affected by service efforts to the client as part of the work carried out by employees and also not affected by employee teamwork. However, employee motivation is influenced by relationships between employees, employee responsibilities at work, employee work behavior. The desire of employees to change jobs is influenced by employee motivation. Indirectly, the desire of employees to change jobs is not influenced by service to the client and teamwork. Conversely, the desire of employees to change jobs is influenced by factors of work relations between employees, employee responsibilities with employee motivation as mediating factors, and employee work behavior factors. Suggestions for researchers can then use export import companies originating from outside Indonesia where blending the culture of the organization will have an important role.
\end{abstract}

Keywords: employee turnover, motivation, organization

\begin{abstract}
ABSTRAK
Persaingan dunia dalam hal ini menunjukkan humum permintaan dan penawaran dalam hal ini berlaku. Perkembangan dunia usaha mampu menyediakan tawaran yang cenderung lebih menarik bagi Sumber Daya Manusia baik yang berpengalaman maupun non-pengalaman. Hal ini membuat karyawan di suatu perusahaan dalam periode tertentu cenderung memiliki pertimbangan untuk berpindah dan memilih tawaran yang lebih menarik dari perusahaan lain. Penelitian ini secara umum bertujuan untuk menganalisis determinan faktor perputaran karyawan. Penelitian ini merupakan penelitian kuantitatif yang menggunakan Structural Equation Modeling (SEM) dengan jumlah sampel sebanyak 50 orang dengan alat analisis yaitu SMART PLS 3.0. Hasil penelitian ini menjelaskan secara pengaruh langsung bahwa motivasi karyawan tidak dipengaruhi oleh upaya layanan terhadap client sebagai bagian dari pekerjaan yang dilakukan karyawan dan juga tidak dipengaruhi oleh kerja sama tim karyawan. Namun demikian motivasi karyawan dipengaruhi oleh hubungan antar karyawan, tanggung jawab karyawan dalam bekerja, perilaku bekerja karyawan. Keinginan karyawan untuk pindah pekerjaan dipengaruhi oleh motivasi karyawan. Secara pengaruh tidak langsung keinginan karyawan untuk pindah pekerjaan tidak dipengaruhi oleh layanan terhadap client dan kerja sama tim. Sebaliknya, keinginan karyawan untuk pindah pekerjaan dipengaruhi oleh faktor hubungan kerja antar karyawan, tanggung jawab karyawan dengan faktor motivasi karyawan sebagai pemediasi, dan faktor perilaku bekerja karyawan. Saran bagi
\end{abstract}


peneliti selanjutnya dapat menggunakan perusahaan ekspor impor yang berasal dari luar Indonesia dimana baur budaya organisasi akan memiliki peranan penting.

Kata kunci: perputaran karyawan, motivasi, organisasi

\section{PENDAHULUAN}

Mercer Indonesia, satu perusahaan terkenal di bidang konsultasi yang salah satu sub bidang bisnisnya yaitu mengenai sumber daya manusia (SDM) melalui riset yang dilakukan tahun 2018 menjelaskan bahwa 1 dari 4 karyawan yang keluar dari perusahaan sebenarnya adalah aset talenta terbaik bagi perusahaan itu sendiri (Movanita, 2018). Penelitian tersebut juga menjelaskan bahwa angka rata-rata karyawan yang berpindah perusahaan di tahun 2018 yaitu sebesar 7,4\% atau menurun sebesar $0,5 \%$ dari tahun sebelumnya. Lebih lanjut juga dijelaskan bahwa beberapa bidang usaha yang cukup tinggi mengalami fenomena perpindahan ini seperti perusahaan berbasis teknologi, jasa keuangan, dan consumer goods. Persaingan dunia usaha dalam hal ini menunjukkan humum permintaan dan penawaran dalam hal ini berlaku. Perkembangan dunia usaha mampu menyediakan tawaran yang cenderung lebih menarik bagi SDM baik yang berpengalaman maupun nonpengalaman. Hal ini membuat karyawan di suatu perusahaan dalam periode tertentu cenderung memiliki pertimbangan untuk berpindah dan memilih tawaran yang lebih menarik dari perusahaan lain. Fenomena ini berbanding lurus sesuai dengan hasil riset Mercer Indonesia dimana 2 (dua) faktor utama penyebab perpindahan karyawan yaitu ketidakjelasan pengembangan karir dan kurang kompetitifnya gaji karyawan.

Sajjad, Ghazanfar, \& Ramzan (2013) menjelaskan bahwa pada industri perbankan, faktor motivasi pada bekerja memiliki peranan yang penting dalam menentukan perpindahan karyawan.

${ }^{1 *}$ Korespondensi Penulis:

Email:yyuniarto@bundamulia.ac.id
Penelitian ini dilakukan pada 4 (empat) bank di Pakistan yaitu Askari Bank, Soneri Bank, Mezaan Bank dan MCB Bank yang melibatkan 106 sampel dari cabang-cabang keempat bank tersebut.

Hasil penelitian ini secara tidak langsung menjelaskan bahwa perusahaan (organisasi) harus memiliki program yang jelas dan terarah dalam mendukung motivasi yang dimiliki karyawan dalam bekerja. Indikator-indikator yang bisa diterapkan organisasi dalam mendukung motivasi karyawan dalam bekerja berdasarkan penelitian tersebut yaitu adanya kerja tim yang baik, tanggung jawab pekerjaan yang diberikan kepada karyawan dan aturan/budaya kerja yang berkaitan dengan perilaku bekerja karyawan di perusahaan.

Kepuasan kerja juga memiliki keterkaitan yang erat dalam menentukan karyawan berpindah perusahaan. Ucho, Mkavga, \& Onyishi (2012) menyatakan faktor utama yang menyebabkan karyawan berpindah perusahaan yaitu kepuasan karyawan dalam bekerja. Park \& Kim (2009) dalam penelitiannya menjelaskan bahwa selain kepuasan kerja, faktor budaya organisasi juga memiliki pengaruh terhdap keinginan karyawan berpindah kerja. Faktor lainnya selain kepuasan kerja yang juga memiliki peranan erat dalam memengaruhi karyawan berpindah pekerjaan adalah procedural justice dan komitmen organisasi (Jahangir, Akhbar, \& Begum, 2006). Tidak hanya faktor-faktor di atas yang telah disebutkan, perbedaan gender yang sekaligus berkaitan dengan job security nyatanya tidak lepas dari penentu tinggi 
tidaknya motivasi karyawan untuk berpindah peusahaan (Kuotsai, 1998).

Budaya organisasi di Indonesia yang mengatur karyawan dalam bekerja nyatanya masih berbeda satu dengan yang lainnya. Hal ini juga menyebabkan masih terdapatnya perbedaan motivasi pada perputaran (turn over) karyawan di perusahaan. Hal ini juga didukung dengan beberapa penelitian yang secara khusus menganalisis fenomena ini di Indonesia. Kartika \& Anindito (2017) dalam penelitiannya di salah satu perusahaan Badan Usaha Milik Negara (BUMN) menyatakan bahwa hubungan kerja antar karyawan memiliki pengaruh pada motivasi kerja karyawan itu sendiri. Hal ini salah satunya dapat menggambarkan juga bahwa hubungan kerja yang baik mampu memberikan kenyamanan dan keamanan dalam bekerja.

Pada perusahaan di bidang hospitality juga tidak terlepas dari faktor penting ini. Tingginya persaingan di bidang jasa perjalanan dan penginapan membuat perusahaan harus memiliki strategi pengelolaan manajemen SDM yang baik supaya program-program kerja usaha yang sudah dirancang dapat dilaksanakan dengan lancar. Octanisa, Sari, \& Ariani (2018) dalam penelitiannya di Intercontinental Bali Resort, menyatakan bahwa untuk meningkatkan motivasi dalam bekerja dilakukan dengan berbagai cara yaitu adanya program pelatihan, apresiasi atau penghargaan bagi karyawan, program media komunikasi bagi internal penilaian akan sikap dan perilaku karyawan dalam bekerja, program konseling bagi karyawan, dan program keselamatan yang berkaitan dengan pekerjaan. Hal yang hampir sama juga dijelaskan oleh Lestari \& Wihardi (2017) yang menjelaskan juga bahwa terdapat keterkaitan antara motivasi bekerja bagi karyawan dengan employee relations. Kedua penelitian tersebut memberikan penjelasan bahwa motivasi kerja dapat didukung dari hubungan yang baik antara karyawan dalam perusahaan yang dalam jangka pendek maupun panjang dapat menekan tingkat perpindahan karyawan.

Pada bidang usaha yang lain misalnya jasa pengiriman (Putrianti, Hamid, \& Mukzam, 2014), fenomena ini secara spesifik membandingkan 2 (dua) faktor penting yaitu motivasi kerja dan kompensasi terhadap keinginan untuk berpindah pekerjaan. Berdasarkan hasil penelitian tersebut dapat dijelaskan bahwa kedua faktor tersebut yaitu motivasi dan kompensasi saling memengaruhi turnover intention. Dari kedua faktor tersebut, nyatanya faktor kompensasi mampu membentuk pengaruh yang lebih kuat terhadap keinginan berpindah pekerjaan bagi karyawan perusahaan tersebut. Hasil penelitian ini juga dapat menjelaskan bahwa program pengelolaan SDM tidak cukup hanya mengandalkan hubungan yang baik yang memotivasi karyawan dalam bekerja. Peranan faktor kompensasi, gaji, ataupun insentif sebagai bentuk reward menjadi faktor yang lebih kuat yang mampu mengendalikan tingkat perpindahan karyawan.

Berdasarkan latar belakang dan masalah-masalah yang telah diidentifikasi di atas, maka penelitian ini secara umum bertujuan untuk menganalisis determinan faktor perputaran karyawan. Hipotesis yang dibentuk pada penelitian ini adalah:

H1: Motivasi karyawan dipengaruhi oleh upaya layanan terhadap client sebagai bagian dari pekerjaan yang dilakukan karyawan, H2: Motivasi karyawan dipengaruhi oleh kerja sama tim karyawan, H3: Motivasi karyawan dipengaruhi oleh hubungan antar karyawan, H4: Motivasi karyawan dipengaruhi oleh tanggung jawab karyawan dalam bekerja, H5: Motivasi karyawan dipengaruhi oleh perilaku bekerja karyawan, H6: Keinginan karyawan untuk pindah pekerjaan dipengaruhi oleh motivasi karyawan, H7: Keinginan karyawan untuk pindah pekerjaan dipengaruhi oleh layanan 
terhadap client dengan faktor motivasi karyawan sebagai pemediasi, H8: Keinginan karyawan untuk pindah pekerjaan dipengaruhi oleh kerja sama tim dengan faktor motivasi karyawan sebagai pemediasi, H9: Keinginan karyawan untuk pindah pekerjaan dipengaruhi oleh faktor hubungan kerja antar karyawan dengan faktor motivasi karyawan sebagai pemediasi, H10: Keinginan karyawan untuk pindah pekerjaan dipengaruhi oleh faktor tanggung jawab karyawan dengan faktor motivasi karyawan sebagai pemediasi, dan H11: Keinginan karyawan untuk pindah pekerjaan dipengaruhi oleh faktor perilaku bekerja karyawan dengan faktor motivasi karyawan sebagai pemediasi

Oleh karena itu penelitian ini diharapkan dapat memberikan manfaat pada kajiankajian teoritis mengenai perkembangan fenomena penyebab karyawan memutuskan untuk berpindah pekerjaan. Secara kajian riset, penelitian ini diharapkan memberikan penjelasan tambahan mengenai fenomena turnover intention khususnya pada perusahaan-perusahaan yang bergerak di bidang ekspor-impor.

\section{METODE PENELITIAN}

Penelitian ini meneliti mengenai determinan faktor perputaran karyawan di perusahan XYZ yang bergerak di bidang usaha eskpor, impor, dan distribusi komoditas pertanian dan bahan baku pakan ternak (jagung, bungkil keledai, dan tepung daging) untuk unggas. Perusahaan ini berlokasi di gedung pusat perbelanjaan Central Park, Jakarta Barat. Faktor-faktor independen yang digunakan dalam penelitian ini yaitu Layanan Terhadap Klien, Kerjasama Pada Tim, Hubungan Antar Karyawan, Tanggung Jawab Pekerjaan dan Perilaku Karyawan Dalam Bekerja. Penelitian ini juga menggunakan faktor Motivasi dalam bekerja sebagai pemediasi.

Penelitian ini menggunakan beberapa pengembangan instrument yang dijelaskan pada tabel 1 berikut:

Tabel 1. Pengembangan Instrumen

\begin{tabular}{|c|c|c|}
\hline Faktor & Indikator & Sumber \\
\hline Turnover Karyawan & $\begin{array}{ll}\text { a. } & \text { Keinginan berpindah } \\
\text { pekerjaan } \\
\text { b. Pencarian pekerjaan } \\
\text { c. Membandingkan pekerjaan } \\
\text { d. Pemikiran untuk keluar }\end{array}$ & Simamora (2004) \\
\hline Layanan Terhadap Klien & $\begin{array}{ll}\text { a. Standar yang jelas } \\
\text { b. Layanan keluhan pelanggan } \\
\text { c. Fleksibilitas layanan } \\
\text { kebutuhan klien } \\
\text { d. Bukti Langsung } \\
\text { e. Kehandalan } \\
\text { f. Ketanggapan } \\
\text { g. Jaminan } \\
\text { h. Empati } \\
\text { i. Kemampuan } \\
\text { j. Sikap } \\
\text { k. Penampilan } \\
\text { l. Perhatian } \\
\text { m. Tindakan } \\
\text { n. Tanggung jawab }\end{array}$ & $\begin{array}{l}\text { Somerville (2011); (Fikri, Wiyani, } \\
\text { \& Suwandaru, 2016) }\end{array}$ \\
\hline Kerja sama Tim & $\begin{array}{l}\text { a. Kepemimpinan Partisipatif } \\
\text { b. Tanggung Jawab Yang } \\
\text { Dibagikan } \\
\text { c. Penyamaan Tujuan }\end{array}$ & Buchholz (2000) \\
\hline
\end{tabular}




\begin{tabular}{|c|c|c|}
\hline & $\begin{array}{ll}\text { d. } & \text { Komunikasi Yang Insentif } \\
\text { e. Fokus Pada Masa Depan Yang } \\
\text { Akan Datang } \\
\text { f. Fokus Pada Tugas } \\
\text { g. Penyerahan Bakat } \\
\text { h. Tanggapan Yang Cepat } \\
\end{array}$ & \\
\hline Hubungan Antar Karyawan & $\begin{array}{ll}\text { a. Komunikasi } \\
\text { b. Kepercayaan } \\
\text { c. Etika } \\
\text { d. Keadilaan } \\
\text { e. Perasaan } \\
\text { f. } \\
\text { g. Harsepsi Dan Keyakinan } \\
\text { h. } & \text { Pemecahan Konflik } \\
\end{array}$ & Laksmana (2014) \\
\hline Tanggung Jawab Pekerjaan & $\begin{array}{l}\text { a. Penyelesaian pekerjaan } \\
\text { dengan baik } \\
\text { b. Kesulitan pekerjaan mampu } \\
\text { diatasi } \\
\text { c. Mampu meminimalisir } \\
\text { kekurangan pekerjaan } \\
\end{array}$ & Desipradani (2015); Yusuf, (2018) \\
\hline Perilaku Karyawan dalam Bekerja & $\begin{array}{l}\text { a. Disiplin Kerja } \\
\text { b. Jujur dalam kerja } \\
\text { c. Komitmen kerja } \\
\text { d. Tanggung jawab terhadap } \\
\text { pekerjaan } \\
\text { e. Kerjasama dengan rekan kerja } \\
\text { f. Mengevaluasi pekerjaan } \\
\text { g. Kemampuan berhubungan } \\
\text { sosial } \\
\text { h. Kualitas pekerjaan } \\
\text { i. Kebiasaan kerja } \\
\text { j. Pengendalian diri } \\
\text { k. Mau menerima arahan } \\
\text { pimpinan } \\
\text { l. Senang menerima tanggung } \\
\text { jawab kerja } \\
\text { m. Kerja sebagai ibadah } \\
\text { n. Melaksanakan kerja sebagai } \\
\text { tugas } \\
\text { o. Dapat mengatasi kendala kerja } \\
\text { p. Dapat menyusun laporan kerja }\end{array}$ & $\begin{array}{l}\text { Taliziduhu (2012); Maulana, } \\
\text { (2013) }\end{array}$ \\
\hline Motivasi & $\begin{array}{l}\text { a. Bentuk Penghargaan } \\
\text { b. Semangat kerja } \\
\text { c. Etos kerja } \\
\text { d. Sikap disiplin }\end{array}$ & Desipradani (2015) \\
\hline
\end{tabular}

Sumber: peneliti, 2019

Penelitian ini merupakan penelitian kuantitatif yang menggunakan Structural Equation Modeling (SEM) dengan jumlah sampel sebanyak 50 orang. Angka ini ditentukan dengan pertimbangan bahwa tidak seluruh karyawan pada saat periode pengumpulan data berhasil dikumpulkan. Oleh karena itu, dari 54 karyawan sebagai populasi di perusahaan XYZ, maka didapat 50 responsen untuk diolah selanjutnya. Instrumen yang digunakan untuk mengumpulkan data pada penelitian ini adalah kuesioner. Penelitian ini menggunakan SMART PLS 3.0 sebagai aplikasi untuk melakukan analisis output data yang diperoleh.

\section{HASIL DAN PEMBAHASAN}

Berdasarkan tabel 2 dapat dijelaskan bahwa indikator yang diperoleh memiliki data yang sahih karena nilai outer loading $>0,70$. Sebelumnya terdapat 3 item yaitu Perilaku bekerja karyawan1, Perilaku bekerja karyawan2, dan Perilaku bekerja karyawan3 yang menunjukkan angka di 
bawah 0,7 sehingga harus dieliminasi agar seluruh item memenuhi angka syarat yang ditentukan.

Tabel 2. Outer Loading

\begin{tabular}{|c|c|c|c|c|c|c|c|c|}
\hline Deskripsi & LTC & KST & HAK & TJK & PERI & MOT & PERPU & Keterangan \\
\hline LTC1 & 0,746 & & & & & & & Sahih \\
\hline LTC2 & 0,862 & & & & & & & Sahih \\
\hline LTC3 & 0,919 & & & & & & & Sahih \\
\hline KST1 & & 0,805 & & & & & & Sahih \\
\hline KST2 & & 0,880 & & & & & & Sahih \\
\hline KST3 & & 0,868 & & & & & & Sahih \\
\hline KST4 & & 0,929 & & & & & & Sahih \\
\hline HAK1 & & & 0,854 & & & & & Sahih \\
\hline HAK2 & & & 0,921 & & & & & Sahih \\
\hline HAK3 & & & 0,805 & & & & & Sahih \\
\hline TJK1 & & & & 0,871 & & & & Sahih \\
\hline TJK2 & & & & 0,790 & & & & Sahih \\
\hline TJK3 & & & & 0,753 & & & & Sahih \\
\hline TJK4 & & & & 0,834 & & & & Sahih \\
\hline PERI4 & & & & & 0,742 & & & Sahih \\
\hline PERI5 & & & & & 0,891 & & & Sahih \\
\hline PERI6 & & & & & 0,822 & & & Sahih \\
\hline MOT1 & & & & & & 0,733 & & Sahih \\
\hline MOT2 & & & & & & 0,820 & & Sahih \\
\hline MOT3 & & & & & & 0,877 & & Sahih \\
\hline MOT4 & & & & & & 0,906 & & Sahih \\
\hline PERPU1 & & & & & & & 0,888 & Sahih \\
\hline PERPU2 & & & & & & & 0,848 & Sahih \\
\hline PERPU3 & & & & & & & 0,775 & Sahih \\
\hline PERPU4 & & & & & & & 0,922 & Sahih \\
\hline PERPU5 & & & & & & & 0,916 & Sahih \\
\hline
\end{tabular}

Sumber: SMART PLS 3.0; $(\mathrm{n}=50)$

Selain pengujian di atas, perlu dilakukan uji kehandalan dengan melihat pada beberapa output seperti Average Variance Extracted

Tabel 3. Uji Kehandalan

\begin{tabular}{lllll}
\hline Faktor & AVE & $\begin{array}{l}\text { Composite } \\
\text { Reliability }\end{array}$ & $\begin{array}{l}\text { Cronbach's } \\
\text { Alpha }\end{array}$ & Status \\
\hline LTC & 0,715 & 0,882 & 0,804 & Handal \\
\hline KST & 0,760 & 0,927 & 0,895 & Handal \\
\hline HAK & 0,742 & 0,896 & 0,826 & Handal \\
\hline TJK & 0,661 & 0,886 & 0,829 & Handal \\
\hline PERI & 0,673 & 0,860 & 0,754 & Handal \\
\hline PERPU & 0,759 & 0,940 & 0,920 & Handal \\
\hline MOT & 0,700 & 0,903 & 0,855 & Handal
\end{tabular}

Sumber: SMART PLS 3.0; $(\mathrm{n}=50)$

Berdasarkan nilai AVE pada tabel diatas, alat ukur yang digunakan untuk penelitian ini sudah tepat, dikarenakan nilai
(AVE), Composite Reliability, dan Cronbach's Alpha. Hasil uji ini dijelaskan pada tabel 3 berikut:

AVE yang diperoleh 0,50. Selanjutnya semua data yang diperoleh juga memiliki data kehandalan, artinya semua instrument pengukuran memiliki ketepatan dengan nilai diatas 0,7. Nilai cronbach's alpha juga menunjukkan keandalan yaitu 0,7 . Artinya instrumen pengukuran yang digunakan memiliki ketepatan.

Uji kesesuaian konstruk pada model penelitian (koefisien determinasi) pada tabel 4 menunjukkan bahwa faktor Motivasi Karyawan dipengaruhi oleh faktor Layanan Terhadap Client, Kerja sama tim, Hubungan 
Antar Karyawan, Tanggung Jawab Karyawan, Perilaku Bekerja sebesar 73,6\% dan sebesar $26,4 \%$ dipengaruhi oleh faktorfaktor lain diluar penelitian ini. Kemudian dari hasil tersebut juga dapat dijelaskan bahwa Keinginan Karyawan berpindah pekerjaan dipengaruhi oleh faktor motivasi yang terbentuk sebesar $21,1 \%$ dan sebesar $78,9 \%$ besarnya sebenarnya disebabkan oleh faktor-faktor lain di luar faktor-faktor yang digunakan dalam penelitian ini.

Tabel 4. Kesesuaian Model

Deskripsi $\quad R$ Square $\quad R$ square Adjusted

\begin{tabular}{lll}
\hline MOT & 0,763 & 0,736 \\
\hline PERPU & 0,227 & 0,211 \\
\hline
\end{tabular}

Sumber: SMART PLS 3.0; $(\mathrm{n}=50)$

Berdasarkan hasil bootstrapping setelah dilakukan uji indikator pada penelitian ini menghasilkan bahwa terdapat 2 hipotesis yang tidak signifikan, dimana nilai minimal $\mathrm{T}$-statistik adalah $>1,96$. Hipotesis yang tidak signifikan adalah kerja sama tim terhadap motivasi dan layanan terhadap client terhadap motivasi.

Tabel 5. Uji Hipotesis

\begin{tabular}{lll}
\hline Deskripsi & T Statistic & Keterangan \\
\hline Direct Effect & & \\
\hline LTC $\rightarrow$ MOT & 1,335 & Tidak berpengaruh; Ha ditolak \\
\hline $\mathrm{KST} \rightarrow$ MOT & 0,549 & Tidak berpengaruh; Ha ditolak \\
\hline HAK $\rightarrow$ MOT & 3,409 & Berpengaruh; Ha diterima \\
\hline TJK $\rightarrow$ MOT & 3,256 & Berpengaruh; Ha diterima \\
\hline PERI $\rightarrow$ MOT & 2,729 & Berpengaruh; Ha diterima \\
\hline MOT $\rightarrow$ PERPU & 5,162 & Berpengaruh; Ha diterima \\
\hline Indirect Effect & & \\
\hline LTC $\rightarrow$ PERPU & 1,298 & Tidak berpengaruh; Ha ditolak \\
\hline KST $\rightarrow$ PERPU & 0,520 & Tidak berpengaruh; Ha ditolak \\
\hline HAK $\rightarrow$ PERPU & 2,909 & Berpengaruh; Ha diterima \\
\hline TJK $\rightarrow$ PERPU & 2,615 & Berpengaruh; Ha diterima \\
\hline PERI $\rightarrow$ PERPU & 2,467 & Berpengaruh; Ha diterima \\
\hline
\end{tabular}

Sumber: SMART PLS 3.0; $(\mathrm{n}=50)$

Berdasarkan hasil output pada tabel 5 dimana angka T-statistik LTC $\rightarrow$ MOT sebesar 1,335 atau lebih kecil dari 1,96 maka Ha ditolak sehingga motivasi karyawan tidak dipengaruhi oleh upaya layanan terhadap client sebagai bagian dari pekerjaan yang dilakukan karyawan. Selanjutnya angka T-statistik KST $\rightarrow$ MOT sebesar 0,549 atau lebih kecil dari 1,96 maka Ha ditolak sehingga motivasi karyawan tidak dipengaruhi oleh kerja sama tim karyawan.
Angka T-statistik HAK $\rightarrow$ MOT sebesar 3,409 atau lebih besar dari 1,96 maka Ha diterima sehingga motivasi karyawan dipengaruhi oleh hubungan antar karyawan. Berikutnya angka T-statistik TJK $\rightarrow$ MOT sebesar 3,256 atau lebih besar dari 1,96 maka Ha diterima sehingga motivasi karyawan dipengaruhi oleh tanggung jawab karyawan dalam bekerja. Selanjutnya angka T-statistik PERI $\rightarrow$ MOT sebesar 2,729 atau lebih besar dari 1,96 maka Ha diterima 
sehingga motivasi karyawan dipengaruhi oleh perilaku bekerja karyawan. Berikutnya angka T-statistik MOT $\rightarrow$ PERPU sebesar 5,162 atau lebih besar dari 1,96 maka Ha diterima sehingga keinginan karyawan untuk pindah pekerjaan dipengaruhi oleh motivasi karyawan itu sendiri.

Hasil output pada tabel 5 juga dapat menjelaskan pengaruh secara tidak langsung. Angka T-statistik LTC $\rightarrow$ PERPU sebesar 1,298 atau lebih kecil dari 1,96 maka Ha ditolak sehingga keinginan karyawan untuk pindah pekerjaan tidak dipengaruhi oleh layanan terhadap client dengan faktor motivasi karyawan sebagai pemediasi. Selanjutnya angka T-statistik KST $\rightarrow$ PERPU sebesar 0,520 atau lebih kecil dari 1,96 maka Ha ditolak sehingga keinginan karyawan untuk pindah pekerjaan tidak dipengaruhi oleh kerja sama tim dengan faktor motivasi karyawan sebagai pemediasi. Berikutnya angka T-statistik $\mathrm{HAK} \rightarrow$ PERPU sebesar 2,909 atau lebih besar dari 1,96 maka Ha diterima sehingga keinginan karyawan untuk pindah pekerjaan dipengaruhi oleh faktor hubungan kerja antar karyawan dengan faktor motivasi karyawan sebagai pemediasi. Kemudian angka T-statistik TJK $\rightarrow$ PERPU sebesar 2,615 atau lebih besar dari 1,96 maka Ha diterima sehingga keinginan karyawan untuk pindah pekerjaan dipengaruhi oleh faktor tanggung jawab karyawan dengan faktor motivasi karyawan sebagai pemediasi. Selanjutnya angka T-statistik $\mathrm{PERI} \rightarrow$ PERPU sebesar 2,467 atau lebih besar dari 1,96 maka Ha diterima sehingga keinginan karyawan untuk pindah pekerjaan dipengaruhi oleh faktor perilaku bekerja karyawan dengan faktor motivasi karyawan sebagai pemediasi.

\section{SIMPULAN}

Dari hasil pembahasan di atas, maka simpulan penelitian ini adalah sebagai berikut:

1. Motivasi karyawan tidak dipengaruhi oleh upaya layanan terhadap client sebagai bagian dari pekerjaan yang dilakukan karyawan

2. Motivasi karyawan tidak dipengaruhi oleh kerja sama tim karyawan

3. Motivasi karyawan dipengaruhi oleh hubungan antar karyawan

4. Motivasi karyawan dipengaruhi oleh tanggung jawab karyawan dalam bekerja

5. Motivasi karyawan dipengaruhi oleh perilaku bekerja karyawan

6. Keinginan karyawan untuk pindah pekerjaan dipengaruhi oleh motivasi karyawan

7. Keinginan karyawan untuk pindah pekerjaan tidak dipengaruhi oleh layanan terhadap client dengan faktor motivasi karyawan sebagai pemediasi

8. Keinginan karyawan untuk pindah pekerjaan tidak dipengaruhi oleh kerja sama tim dengan faktor motivasi karyawan sebagai pemediasi

9. Keinginan karyawan untuk pindah pekerjaan dipengaruhi oleh faktor hubungan kerja antar karyawan dengan faktor motivasi karyawan sebagai pemediasi

10. Keinginan karyawan untuk pindah pekerjaan dipengaruhi oleh faktor tanggung jawab karyawan dengan faktor motivasi karyawan sebagai pemediasi

11. Keinginan karyawan untuk pindah pekerjaan dipengaruhi oleh faktor perilaku bekerja karyawan dengan 
faktor motivasi karyawan sebagai pemediasi

\section{DAFTAR PUSTAKA}

Buchholz, S. (2000). Creating The High Performance Team. Canada: John Wiley \& Sons, Inc.

Desipradani, G. (2015). Variabel Berpengaruh Terhadapmotivasi Kerja Pegawai. Majalah Ekonomi, XX(2), 1411-9501.

Fikri, S., Wiyani, W., \& Suwandaru, A. (2016). Pengaruh Kualitas Pelayanan Terhadap Kepuasan Dan Loyalitas Mahasiswa (Studi pada Mahasiswa Strata I Fakultas Ilmu Sosial dan Ilmu PolitikUniversitas Merdeka Malang). Jurnal Bisnis dan Manajemen, 3(1), 120-134.

Jahangir, N., Akhbar, M., \& Begum, N. (2006). The Impact of Social Bases, Procedural Justice, Job Satisfaction, and Organizational Commitment on Employees' Turnover Intention. South Asian Journal of Management, 13(4), 72.

Kartika, R., \& Anindito, A. (2017). Penerapan Program Employee Relations Dalam Meningkatkan Motivasi Kerja Karyawan Di PT. PLN (PERSERO) PUSLITBANG. Communicology, 5(2), 1-26.

Kuotsai, T. (1998). Employee Turnover Intention and Professional Orientation: A Study of Detention Worker. Public Administration Quarterly, 22(2).

Laksmana, K. (2014). Peran Budaya Organisasi Dalam Membangun Employee Relations Pada Cv. Z Di Surabaya. AGORA, 2(1).
Lestari, M., \& Wihardi, D. (2017). Pengaruh Kegiatan Employee Relations Terhadap Motivasi Kerja Karyawan (Survei Pada Karyawan PT. Smailing Tour di Jakarta). PANTAREI, 1(3).

Maulana, T. (2013). Analisa Perilaku Kerja Karyawan Di De Boliva Surabaya Town Square. Jurnal Hospitality dan Manajemen Jasa, 563-577.

Movanita, A. N. (2018, Desember 7). Ekonomi. Retrieved Agustus 1, 2019, from www.kompas.com: https://ekonomi.kompas.com/read/2 018/12/07/101938426/1-dari-4pegawai-resign-punya-keahlianyang-dibutuhkanperusahaan?page $=$ all

Octanisa, D. S., Sari, N. R., \& Ariani, N. (2018). Pengaruh employee relation terhadap motivasi kerja karyawan intercontinental bali resort. Jurnal Kepariwisataan Dan Hospitalitas, 2(1), 106-125.

Park, J., \& Kim, T. (2009). Do Types of Organizational Culture Matter in Nurse Job Satisfaction and Turnover Intention? Leadership in Health Services, 22(1), 20-38.

Putrianti, A. D., Hamid, D., \& Mukzam, M. D. (2014). Pengaruh Kompensasi Dan Motivasi Kerja Terhadap Turnover Intention (Studi Pada Karyawan PT. TIKI Jalur Nugraha Ekakurir Pusat Malang). Jurnal Administrasi Bisnis (JAB), 12(2), 19.

Sajjad, A., Ghazanfar, H., \& Ramzan, M. (2013). Impact of Motivation on Employee Turnover in Telecom Sector of Pakistan. Journal of Business Studies Quarterly, 5(1), 76-92. 
Simamora, H. (2004). Manajemen Sumber Daya Manusia. Yogyakarta: STIE YKPN.

Somerville, K. (2011). Strategies to improve client service: Exemplars in the Canadian federal government. The Innovation Journal: The Public Sector Innovation Journal, 16(2), 116.

Taliziduhu, N. (2012). Pengantar Teori Pengembangan Sumber Daya Manusia. Rineka Cipta.
Ucho, A., Mkavga, T., \& Onyishi, I. (2012). Job Satisfaction, Gender, Tenure, and Turnover Intentions among Civil Servants in Benue State. Interdisciplinary Journal of Contemporary Research in Business, 3(11), 378-387.

Yusuf, N. (2018). Pengaruh Kepemimpinan, Tanggung Jawab, Kedisiplinan Dan Kerjasama Terhadap Kinerja Pegawai di Universitas Gorontalo. Gorontalo Development Review, 1(1), 15-28. 